\title{
ENTRE EL ENCICLOPEDISMO Y LA DISCIPLINA CIENTÍFICA
}

\author{
BETWEEN ENCYCLOPEDISM AND SCIENTIFIC DISCIPLINE \\ (iD) Edgar Gutiérrez Gómez ${ }^{*}$ \\ egutierrez@unah.edu.pe \\ ${ }^{1}$ Universidad Nacional Autónoma de Huanta, Ayacucho, Perú
}

*Correspondencia: Edgar Gutiérrez Gómez. Email: egutierrez@unah.edu.pe

La revista de investigación científica Puriq de la Universidad Nacional Autónoma de Huanta, se funda en los albores donde CONCYTEC intensifica la sobrevaloración de escritos científicos. La producción en las universidades del Perú resulta masificada y se sustenta en el marco de las exigencias científicas para calificar como docentes investigadores, con ciertas prerrogativas en la labor universitaria. La proliferación de revistas de investigación científica; también obedece a esa necesidad. Es así, que la revista Puriq se funda con un carácter multidisciplinar con un propósito de sostenibilidad en el tiempo. Mantenerse en el tiempo es la apuesta más urgente de toda revista y sus editores, pues la producción académica es un símil a las modas de fenómeno mundial que se disipa en la sociedad líquida.

Toda fundación es sacrificada, con una incertidumbre de camino sinuoso, que se fundamenta para seguir en una sociedad. René Girard, citado como: "Para constituir una sociedad y una civilización el hombre debe haber sacrificado, si no por completo, por lo menos en gran parte, su lado agresivo y violento. Este sacrificio quedó, naturalmente, incompleto". (Rozzi, 2010, p.67). Un trabajo que deposita el lado agresivo del hombre en escribir manuscritos, con fino propósito de postular a una revista, es merecedor de un premio al sacrificio desplegado. Con el paso del tiempo, las sociedades fundacionales que refiere Girard, se hará patentes de un conglomerado orden de disciplina científica en nuestro caso. En esa consideración, auguramos a nuestros colaboradores de otras áreas del saber, que la revista Puriq, solo publicará a partir de su próximo número, artículos en la disciplina de Ciencias Humanas. Esperamos que el lado violento de escribir del hombre se convierta en situación completa para postular a otras revistas de su disciplina específica.

En ese fundamento, nuestro interés es estrictamente académico y científico para seguir postulando a los repositorios científicos que exigen calidad y disciplina en la investigación. Si algo nos preciamos, es de valorar la ciencia como una deuda con los enciclopedistas Diderot y D'Alembert, quiénes cimentaron las raíces del enciclopedismo. El fenómeno adverso de la actualidad, exige la especialización en una disciplina científica específica que redunde en un sustento académico del mundo cada vez heterogéneo. El fenómeno mundial atípico, exige a los gobernantes o postulantes a la gobernatura del país, que su equipo de trabajo impulse la ciencia en el Perú. "A pocos meses de las elecciones generales, ocho candidatos a la presidencia participaron del Encuentro Científico Internacional de Verano (ECIv 2021) para debatir y argumentar sus planes de gobierno sobre ciencia y tecnología para impulsar el desarrollo del país”. (República, 2021). Es una iniciativa interesante a portas de las elecciones; claro, deberían estar sus representantes en 
el área específica de la ciencia. Un candidato político de ninguna forma es un enciclopedista en tiempo de la investigación disciplinar especificada.

El avance progresivo de nuestro trabajo, se evidencia en el creciente porcentual de postulantes de manuscritos para su evaluación por pares en nuestra revista Puriq. Agradecemos que esas iniciativas se sumen a la investigación científica en el área de Humanidades que plantea continuar nuestra editorial. La recurrencia a la ciencia, después del exagerado interés por la acumulación de la riqueza individual, se acrecienta en el escenario del fenómeno mundial.

La investigación en humanidades, forma y forja al hombre con un conocimiento cabal sobre su existencia en el planeta y su repentina partida a la eternidad. Estamos seguro que los confinamientos han producido ciencia, como: "Si a Diderot no le hubieran encarcelado al circular sus primeros escritos, a buen seguro no se hubiera empeñado tanto en sacar adelante su Enciclopedia, cuya influencia resulta decisiva para combatir los prejuicios y la superstición de su época, favoreciendo así el advenimiento de la Revolución Francesa". (Aramayo, 2020). Cerramos épocas, vidas, años y escenarios de trabajo por espacio mejor resguardado, es una sociedad líquida de acomodos constantes, antes de perecer en el fango científico de la enciclopedia. Invitamos ser partícipe de nuestras apreciaciones del último contenido multidisciplinar que publicamos en este número.

\section{REFERENCIAS BIBLIOGRÁFICAS}

Aramayo, R. R. (20 de 06 de 2020). Paseos y casualidades que cambiaron la historia del pensamiento (cual manzana de Newton). BBC NEMS.

República, L. (05 de enero de 2021). Candidatos a la presidencia expusieron planes sobre ciencia y tecnología. La República.

Rozzi, M. (2010, p.67). La interpretación filosófica y política de La violencia y lo sagrado de René Girard, y su influencia en la antropología latinoamericana. Universitas Philosophica, 67. 